\title{
Extracranial ligation of ethmoidal arteries before resection of giant olfactory groove or planum sphenoidale meningiomas: 3 illustrative cases with a review of the literature on surgical techniques
}

\author{
Sunil Manjila, M.D., ${ }^{1}$ Efrem M. Cox, M.D., ${ }^{1}$ Gabriel A. Smith, M.D. ${ }^{1}$ \\ Mark Corriveau, B.A., ${ }^{1}$ Nipun Chhabra, M.D., ${ }^{3}$ Freedom Johnson, M.D., 2 \\ and Robert T. Geertman, M.D., Ph.D. ${ }^{1}$ \\ Departments of ${ }^{I}$ Neurosurgery and ${ }^{2}$ Otolaryngology-Head \& Neck Surgery, MetroHealth Hospital, Case \\ Western Reserve University, Cleveland, Ohio; and ${ }^{3}$ Department of Otolaryngology-Head \& Neck Surgery, \\ Massachusetts Eye and Ear Infirmary, Boston, Massachusetts
}

Object. There are several surgical techniques for reducing blood loss-open surgical and endoscopic-prior to resection of giant anterior skull base meningiomas, especially when preoperative embolization is risky or not technically feasible. The authors present examples of an institutional experience using surgical ligation of the anterior and posterior ethmoidal arteries producing persistent tumor blush in partially embolized tumors.

Methods. The authors identified 12 patients who underwent extracranial surgical ligation of ethmoidal arteries through either a transcaruncular or a Lynch approach. Of these, 3 patients had giant olfactory groove or planum sphenoidale meningiomas. After approval from the institution privacy officer, the authors studied the medical records and imaging data of these 3 patients, with special attention to surgical technique and outcome. The variations of ethmoidal artery foramina pertaining to this surgical approach were studied using preserved human skulls from the HamannTodd Osteological Collection at the Museum of Natural History, Cleveland, Ohio.

Results. The extracranial ligation was performed successfully for control of the ethmoidal arteries prior to resection of hypervascular giant anterior skull base meningiomas. The surgical anatomy and landmarks for ethmoidal arteries were reviewed in anthropology specimens and available literature with reference to described surgical techniques.

Conclusions. Extracranial surgical ligation of anterior, and often posterior, ethmoidal arteries prior to resection of large olfactory groove or planum sphenoidale meningiomas provides a safe and feasible option for control of these vessels prior to either open or endoscopic resection of nonembolized or partially embolized tumors.

(http://thejns.org/doi/abs/10.3171/2013.10.FOCUS13327)

\section{KEY WORDS • skull base meningioma • olfactory groove • anterior ethmoidal artery $\quad$ - endoscopic ligation • posterior ethmoidal artery • embolization - microsurgical anatomy}

$\mathrm{S}$ INCE large anterior skull base meningiomas are typically highly vascular, resection of these lesions is often complicated by significant blood loss. ${ }^{34,41}$ In anterior skull base meningiomas, the vascularity is derived from dural, transosseous, or pial supply. The classic angiographic appearance of a spoke wheel is derived from the primary meningeal supply from the dura mater

\footnotetext{
Abbreviations used in this paper: $\mathrm{ACA}=$ anterior cerebral artery; $\mathrm{AEA}=$ anterior ethmoidal artery; $\mathrm{ECA}=$ external carotid artery; EEEA = extended endonasal endoscopic approach; ICA = internal carotid artery; MMA = middle meningeal artery; PEA = posterior ethmoidal artery.
}

of tumor origin, while the pial supply could be due to cortical invasion or parasitization of adjacent arteries. The exact site of tumor origin can aid with prediction of the primary blood supply. For example, meningiomas of the olfactory groove and planum sphenoidale receive blood supply from dural branches of the internal carotid artery (ICA, including ethmoidal arteries from the ophthalmic branch) while those arising from the sphenoid wing and remaining anterior fossa are most often predominantly supplied by middle meningeal arteries (MMAs, arising from the external carotid artery [ECA]). The preoperative endovascular embolization of the primary feeding vessel in meningiomas has been shown to appreciably reduce 


\section{S. Manjila et al.}

surgery time, intraoperative bleeding, and hence blood transfusion. ${ }^{33}$ However, Bendszus et al. demonstrated that only complete embolization had an effect on blood loss. ${ }^{2}$ Safe embolization is often limited by dangerous arterial anastomoses between ECA and ICA branches or an aberrant origin of the MMA from the ophthalmic artery or vice versa. Giant meningiomas of the olfactory groove and planum sphenoidale also receive collaterals from the meningeal branches of the ICA, MMA (frontal and sphenoidal branches), and distal maxillary artery (sphenopalatine branch), all of which can put vision at risk due to dangerous anastomoses.

When giant olfactory groove or planum sphenoidale tumors are resected via a transcranial approach, removal of the orbital rims can offer low basal access and working space below the frontal lobes without significant brain retraction. The subfrontal approach allows direct access and shortens the distance to the tumor, while providing broad exposure. It is easy to devascularize anterior skull base meningiomas at the basal dural attachment without significant brain retraction if the lesion is small in size. In large meningiomas of the anterior cranial fossa, it is often difficult to provide retraction or relaxation of the brain until a sizeable internal decompression of tumor is performed, especially when there is tumor-induced parenchymal edema and brain shift. Apart from augmented vascularity, the feeding ethmoidal vessels are often hypertrophied or have increased flow compared with normal-sized ethmoidal arteries. Especially in patients with serious medical comorbidities, significant blood loss can be avoided with our technique of vascular control prior to violation of the tumor capsule. Additionally, it is not always possible to achieve direct access to the ethmoidal arteries due to the size and invasion of the anterior fossa skull base that is seen in many of these tumors.

We identified 12 patients who underwent extracranial surgical ligation of the ethmoidal arteries through either a transcaruncular or a Lynch approach at our institution. We present our experience with 3 cases in which transcaruncular and Lynch approaches were used to ligate the anterior, and when possible, posterior, ethmoidal arteries to diminish blood loss during resection of olfactory groove and planum sphenoidale meningiomas. The institution privacy officer granted approval for us to study the medical records and imaging data in these patients. This technique has been used in nonneurosurgical conditions such as epistaxis, nasopharyngeal carcinoma, sphenoid sinus carcinoma, and other craniofacial tumor resections involving maxillectomy or orbital exenteration.

\section{Illustrative Cases}

\section{Case 1}

This 50-year-old woman was admitted with a several-year history of personality changes and intermittent headaches. She presented to the emergency department with new-onset ataxia, bitemporal hemianopia, and urinary incontinence that developed over a few weeks. A noncontrast head CT scan revealed a $7-\mathrm{cm}$ mass originating along the olfactory groove/planum sphenoidale, and subsequent MRI with Gd confirmed a homogeneously enhancing mass with perilesional edema in the anterior and middle cranial fossas abutting the suprasellar cistern, consistent with a giant meningioma (Fig. 1A-D). Diagnostic cerebral angiography revealed marked hypervascularity of the lesion with parasitization of the anterior cerebral arteries (ACAs) and additional supply from the bilateral anterior ethmoidal arteries (AEAs). A decision was made to attempt to first devascularize the tumor using microcatheter embolization techniques. Partial devascularization was achieved with successful embolization of bilateral maxillary arteries using Avitene (Bard, Inc. [Davol]) (Fig. 1E-J). The following day, the patient was taken to the operating room and the otolaryngology service performed bilateral AEA ligations using standard Lynch incisions. Electrocautery was used through the soft tissue down to the periosteum of the medial orbital walls. The periorbital contents were retracted laterally, and the frontoethmoidal suture line was identified. Using blunt dissection posteriorly from the suture line, the AEAs were identified approximately $22 \mathrm{~mm}$ posterior to the lacrimal crest. A hemostatic clip followed by bipolar cautery was then used to ligate the vessels bilaterally. The incisions were closed, and then the patient's head was positioned in a Mayfield headholder. A bicoronal incision was made followed by a bifrontal craniotomy. A large bifrontal dural opening was undertaken, and the tumor was shrunk and debulked internally with bipolar electrocautery and Cavitron Ultrasonic Suction Aspirator (SOMA Technology, Inc.). The tumor capsule was then resected along all margins except for the most posteroinferior segment involving the sella, optic chiasm, and bilateral ICAs, where the tissue planes were poorly visualized. The frontal sinuses were exenterated, and a vascularized pericranium flap was placed over the defect. The estimated blood loss was 1.1 L. Postoperative MRI revealed a subtotal resection with a thin residual rim of tumor encapsulating the left ICA. The patient tolerated the procedure well and was discharged to cognitive rehabilitation. The patient underwent follow-up for 3 years postoperatively and remained asymptomatic from the residual tumor, which has remained stable in size on follow-up imaging.

\section{Case 2}

This 53-year-old woman presented with acute changes in vision over 6-8 weeks along with personality changes. She was noted to have bilateral optic disc atrophy on funduscopic examination and no lateralizing neurological deficits. Noncontrast CT revealed a large mass along the anterior skull base likely originating from the planum sphenoidale. Magnetic resonance imaging with $\mathrm{Gd}$ revealed a $6.5 \times 5.6 \times 4.8-\mathrm{cm}$ planum sphenoidale meningioma abutting the optic chiasm and displacing both ICAs posteriorly. Significant hyperostosis of the adjacent planum sphenoidale was also noted (Fig. 2A-D). Diagnostic cerebral angiography revealed marked hypervascularity of the tumor, supplied by the bilateral internal maxillary arteries and ethmoidal branches. A decision was made to attempt to first partially devascularize the tumor using endovascular microcatheter embolization of the ECA supply. Embolization was performed through the maxil- 


\section{Ethmoidal artery ligation before meningioma resection}
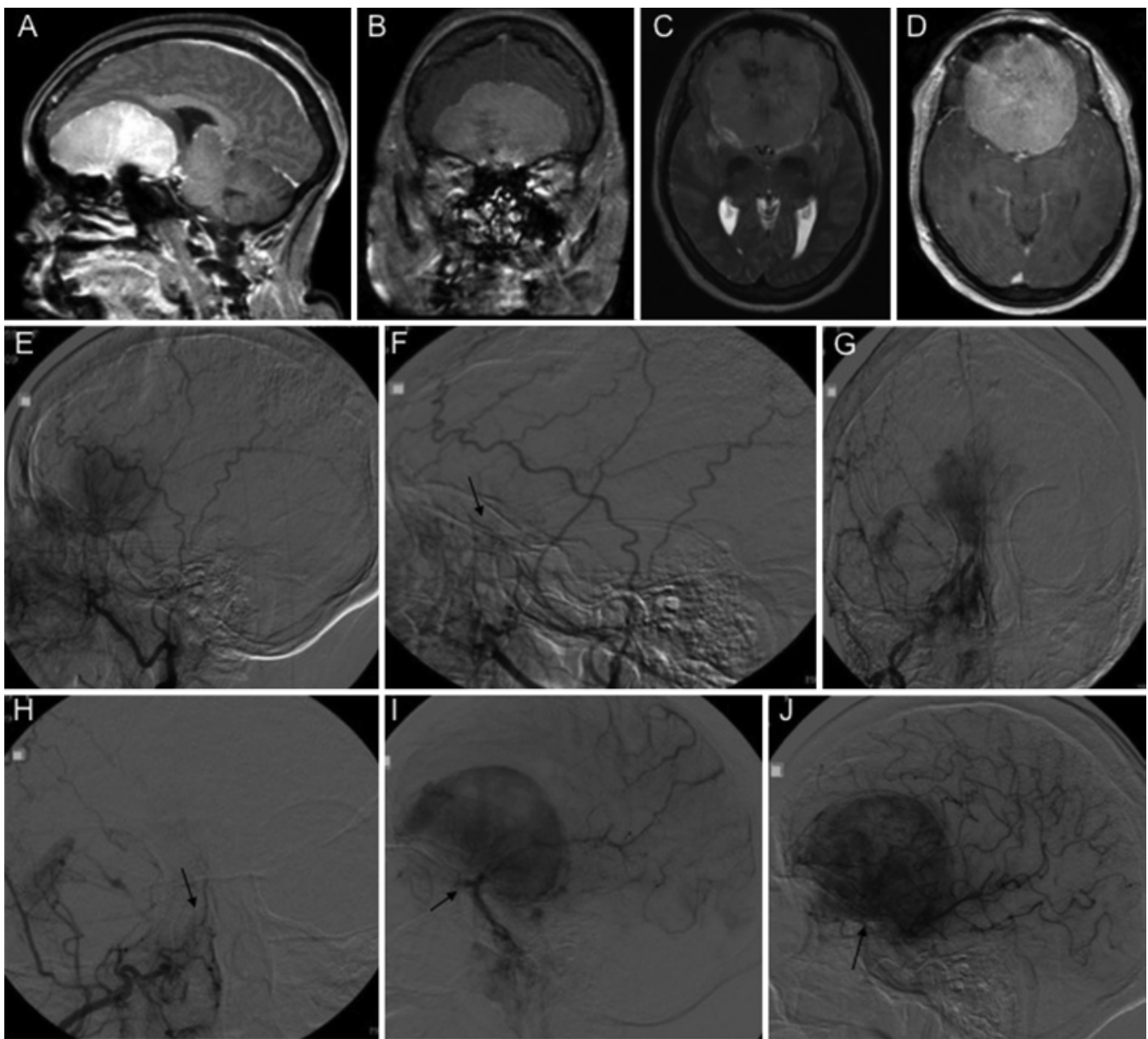

FIG. 1. Magnetic resonance images and angiograms of an olfactory groove/giant planum sphenoidale meningioma. A: Contrast-enhanced sagittal MR image showing the extent of the lesion with skull base hyperostosis. B: Contrast-enhanced coronal MR image showing the relationship of the tumor to ethmoidal air cells. C: Axial T2-weighted image showing mass effect and rim of perilesional edema. D: Contrast-enhanced axial image showing the vascularity of the lesion. E-H: Angiograms (lateral $[\mathrm{E}$ and $\mathrm{F}]$ and posteroanterior $[\mathrm{G}$ and $\mathrm{H}]$ views of internal maxillary artery injection before and after embolization. I and $\mathrm{J}$ : Angiograms showing remarkably delayed tumor blush on ICA injection despite embolization of maxillary artery branches. Arrows in images $\mathrm{F}, \mathrm{H}, \mathrm{I}$, and $\mathrm{J}$ indicate the site of tumor blood supply from skull base attachments, before and after internal maxillary artery embolization.

lary artery bilaterally, and Avitene was injected until cessation of antegrade flow. However, the tumor blush persisted after embolization of the maxillary arteries (Fig. $2 \mathrm{E}-\mathrm{J}$ ). The following day, the patient was taken to the operating room and the otolaryngology service performed bilateral AEA ligation using a transcaruncular approach. First, the [lacrimal] caruncle was identified, and monopolar electrocautery was used to make an incision just laterally. Next, the lacrimal fossa was identified and dissection was carefully performed posteromedially in the avascular fascial plane. The frontoethmoidal suture line was identified, and the periosteum was incised bilaterally. Subperiosteal dissection was then undertaken posteriorly, and the AEAs were identified bilaterally and coagulated in a similar fashion as described in Case 1. The incisions were closed and the patient was then placed in a Mayfield headholder. The head was turned $30^{\circ}$, a pterional incision was made, and a standard right-sided orbitozygomatic craniotomy was performed. A large standard dural opening was made and the tumor was identified after careful dissection of the sylvian fissure. The tumor was resected all the way down to the posteroinferior tumor capsule seen along the right $A_{1}, A_{2}$, and $M_{1}$ vessels. A plane was then identified along the inferior margin, and the tumor was resected by piecemeal debulking with the aid of the Cavitron Ultrasonic Aspirator. The optic canals were then identified, and the tumor capsule was carefully resected posterior to the optic chiasm. Next, attention was turned to the left ICA where the last remaining segment of tumor was resected carefully. The dura of the anterior cranial fossa was then resected, and the hyperostotic planum sphenoidale was drilled away using a 5-mm diamond bur with care to not violate the ethmoidal sinuses from above. A pericranium flap and DuraGen (Integra Neurosciences) onlay were placed along the floor and the dura mater was approximated. The estimated blood loss was $450 \mathrm{ml}$. The patient tolerated the procedure well, and postoperative MRI findings were consistent with a gross-total resection. The patient's postoperative course was complicated by cerebrospinal rhinorrhea requiring lumbar drainage for 1 

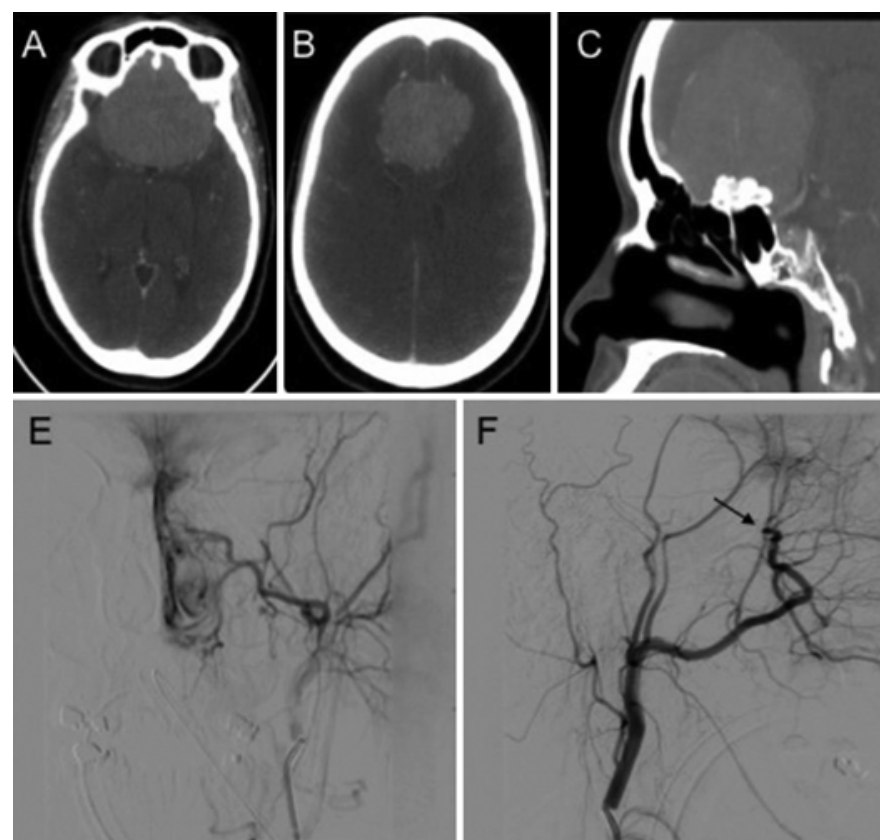

$\mathrm{F}$
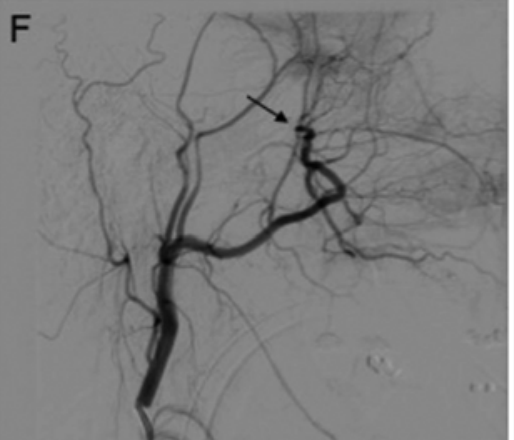

$\mathrm{H}$
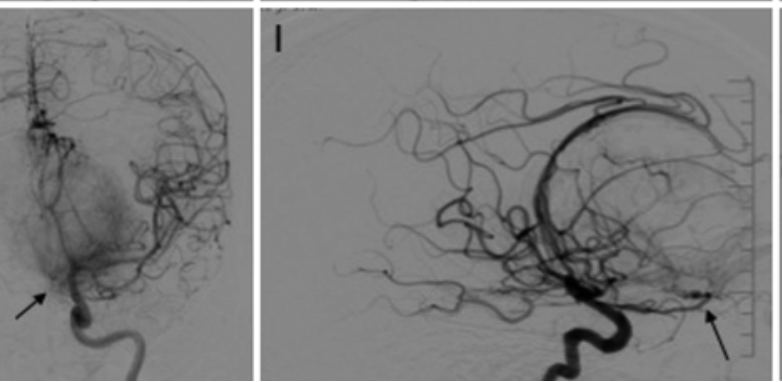

FIG. 2. Computed tomography and angiograms of a giant planum sphenoidale meningioma. A and B: Axial contrast-enhanced images of the tumor. $\quad$ C and D: Sagittal and coronal images with bony hyperostosis. $\quad E$ and F: Angiograms showing the maxillary artery branches (arrow) supplying the tumor. G: Angiogram showing superselective injection of the internal maxillary artery feeder (arrow) prior to embolization. H-J: Angiograms showing delayed residual tumor blush with supply from the ethmoidal artery arising from the ophthalmic artery (arrows).

week; however, this resolved without further surgical intervention. She was discharged to cognitive rehabilitation in stable condition. At the 1-year follow-up, she continued to do well, and her vision loss had partially improved. No tumor recurrence was identified on follow-up imaging.

\section{Case 3}

This is a 46-year-old man who presented with newonset headaches was found on MRI to have a $5.5 \times 5.2$ $\times 3.8-\mathrm{cm}$ homogeneously enhancing mass along the planum sphenoidale consistent with a large olfactory groove/ planum sphenoidale meningioma. The tumor was abutting the optic chiasm and both ICAs (Fig. 3A). The patient was started on high-dose dexamethasone, and he underwent preoperative cerebral angiography for possible embolization. The right maxillary artery was found to be the predominant feeding vessel, along with some perforating ethmoidal branches. The maxillary artery feeders were embolized using Avitene injections (Fig. 3D-F). The patient was then taken to the operating room the next day for a multidisciplinary approach to resection. The otolaryngologists used a standard Lynch incision to ligate the right anterior and posterior ethmoidal arteries. An incision was made and electrocautery was used down to the periosteum of the medial orbital wall. The periorbital contents were identified and retracted laterally. Using blunt dissection posteriorly, the frontoethmoidal suture line was exposed and the AEA was identified and coagulated. Dissecting further posteriorly, the posterior ethmoidal artery (PEA) was identified approximately $15 \mathrm{~mm}$ behind the AEAand was ligated as well. The patient was then placed in a Mayfield headholder, and a standard bicoronal incision and bifrontal craniotomy was performed maintaining an intact pericranial flap. A large dural opening was made and the tumor was identified and debulked internally at first from the right side. After debulking, the capsule of tumor was freed from frontal lobe and falx and then inferiorly down to the cribriform plate. After similar techniques on the left side, the posterior margins superiorly were identified and resected safely away from the ACAs. Great care was then taken to carefully dissect the posteroinferior margins abutting the optic canals, tuberculum sella, and bilateral ICAs. The estimated blood loss was $580 \mathrm{ml}$. Postoperatively the patient did well, and MRI imaging confirmed a gross-total resection with mild 


\section{Ethmoidal artery ligation before meningioma resection}
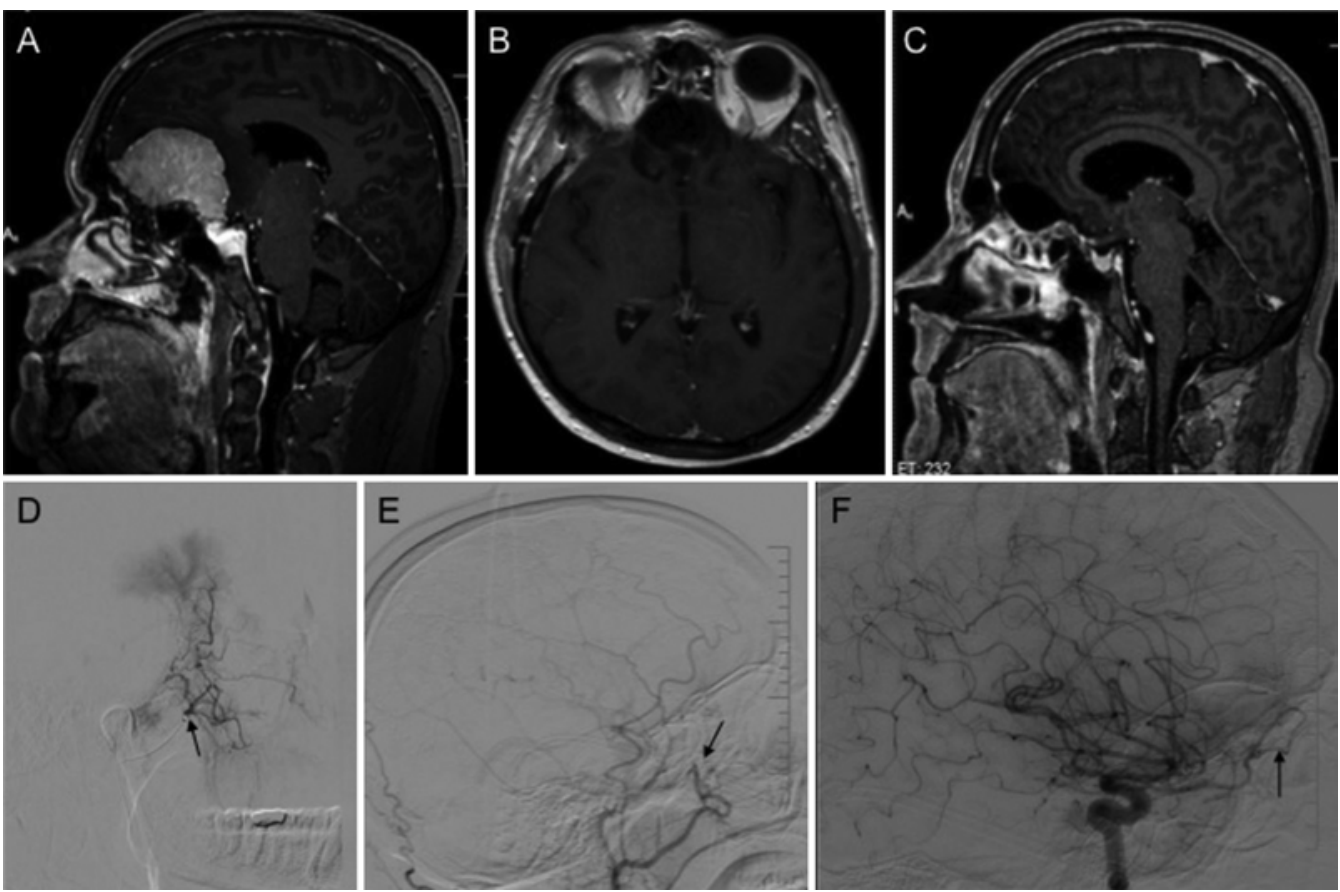

FIG. 3. Magnetic resonance images and angiograms of a giant olfactory groove/planum sphenoidale meningioma. A: Sagittal contrast-enhanced image of the meningioma. B and C: Postoperative axial and sagittal images showing mild basal pneumocephalus and no residual tumor. D: Angiogram showing superselective injection of the right maxillary artery. The arrow indicates the vascular pedicle. E: Angiogram revealing successful embolization of the internal maxillary artery feeder. The arrow shows attachment of the tumor at the skull base. F: Residual tumor blush in relation to the ethmoidal artery (arrow) is noted on the ICA injection.

basal pneumocephalus (Fig. 3B and C). At the 6-month follow-up the patient continued to improve and had resumed normal activities of daily living. Surveillance imaging at 1 year demonstrated no recurrence.

\section{Discussion}

Resection of giant anterior skull base meningiomas is often met with a dreaded challenge of extreme hypervascularity of the lesion, supplied by the AEAs and PEAs, which cannot always be safely embolized. While the precise rate of visual compromise from endovascular intervention of the ethmoidal arteries is difficult to ascertain, a review of the literature suggests that up to $10 \%$ of patients may experience visual complications. ${ }^{35}$ Large olfactory groove and planum sphenoidale meningiomas especially pose a surgical challenge due to difficulty in getting around the tumor and obtaining hemostasis at the skull base early in the operation. The former arise from the cribriform plate as well as the frontosphenoid suture, while the latter arise from the planum sphenoidale. The location at the anterior skull base makes them amenable to a bicoronal subfrontal, oblique subfrontal, interhemispheric, or classic pterional transsylvian approach. ${ }^{6,8,25,26}$ The subfrontal approach is popular due to easier access to the basal dural blood supply from the ethmoidal arteries, permitting earlier devascularization while providing the best view for cranial base repair with a pericranial flap. Apart from gaining control of the ethmoidal blood supply early during the surgery, endoscopic options for resection of these lesions are gathering momentum because of their minimally invasive nature and the decreased morbidity from reduced brain retraction.

Olfactory groove and planum sphenoidale meningiomas are located anteriorly in the skull base supplied by both anterior and posterior ethmoidal arteries (predominantly anterior), apart from a meningeal branch of the ophthalmic artery and/or an anterior branch of the MMA. ${ }^{6,8,25}$ These lesions are differentiated from posteriorly placed tuberculum sellae meningiomas in that the latter do not have a significant AEA supply and the olfactory nerves are superolateral, chiasm is inferolateral, and the ACA lies posterior or posterosuperior relative to the tumor. When the olfactory groove meningiomas reach a giant size, there are occasionally branches from the ACAs and anterior communicating arteries that are also supplying them. .,25,32 $^{2}$

The AEA is an orbital branch of the third segment of the ophthalmic artery and runs between the superior oblique and medial rectus muscles before leaving the orbit at the anterior ethmoidal foramen, together with the anterior ethmoidal nerve, to enter the roof of the ethmoidal sinus. It crosses the cribriform plate and enters the nose through a tiny slit adjacent to the crista galli to become the dorsal nasal artery, and also enters the cranial cavity near the cribriform plate to supply the dura mater of the anterior cranial fossa and the anterior part of the falx cerebri. The AEA supplies the anterior and middle ethmoidal air cells as well as mucosa of the frontal sinus. The PEA, when present, arises from the first segment of the ophthalmic artery and travels in the posterior ethmoidal canal to supply the posterior ethmoidal cells, 


\section{S. Manjila et al.}

posterior lamina cribrosa, planum sphenoidale, and nasal septum. Occasionally, it sends a meningeal branch to the cranial dura mater. Thus, the AEAs provide significant blood supply to anterior skull base meningiomas. It is often dangerous to embolize the AEA because it can cause retrograde migration of particles, which results in blindness from occlusion of the ophthalmic artery, although anecdotal successful cases are reported. ${ }^{43}$ Turner et al. and Kunikata and Tamai have demonstrated sequential branch retinal artery occlusion and cilioretinal artery occlusion, respectively, leading to severe visual loss. ${ }^{22,44}$ Hence, the surgical control of the ethmoidal arteries has become a useful adjunct in reducing blood loss during resection of partially embolized anterior skull base lesions where ECA branches are already taken down and subsequent ICA injections show a persistent tumor blush.

A bicoronal subfrontal approach is commonly used for giant meningiomas in the anterior cranial fossa, followed by a unilateral oblique subfrontal, interhemispheric, or classic pterional transsylvian approach. During transcranial surgery, there are multiple areas of proximal control that are described for controlling the ethmoidal arteries. White et al. presented a cadaver study with illustrative surgical cases where unilateral and bilateral single-piece frontoorbital craniotomies were done for olfactory groove meningiomas. ${ }^{46}$ They demonstrated proximal control of the ethmoidal arteries in 3 sites: in the lamina papyracea of the medial orbital wall at the anterior ethmoidal foramen along the frontoethmoidal suture at an average distance of $22 \mathrm{~mm}$ from the lacrimal crest, at the lateral ethmoidal wall as the AEA traverses the anterior ethmoidal foramen and travels in the anterior ethmoidal canal, and also extradurally at the cribriform plate where it travels across the ethmoidal sinus to reach the cribriform plate, which in turn lies anterior to the anterior ethmoidal foramen. ${ }^{46} \mathrm{McDermott}$ et al. demonstrated the utility of transcranial, extradural access through the medial orbital wall using subperiosteal and subperiorbital dissection after a bicoronal flap. ${ }^{27}$ They demonstrated the safety and feasibility of controlling both anterior and posterior ethmoidal arteries in this method. However, we feel that performing a large single-piece craniotomy or retracting posteriorly on the frontal lobes with an unresected giant olfactory groove meningioma would predispose the brain to significant damage from retraction or manipulation prior to reaching the ethmoidal feeders in the skull base. Furthermore, resection of the juxtasellar portion of tumor as well as preservation of ACAs draping the tumor posterosuperiorly would be more amenable to a transcranial extracapsular extraarachnoid dissection using conventional bimanual microsurgical techniques. Considering the large size and remarkable mass effect of these lesions, we opted to perform an extracranial approach for ethmoidal artery ligation, over an intracranial intradural or extradural approach.

Extracranial surgical access to the anterior and posterior ethmoidal arteries can be difficult to obtain, and methods for approaching them have undergone numerous iterations, both open surgical and endoscopic (Figs. 4 and 5). Traditional medial orbital wall access was originally described by R. C. Lynch in 1921 and was the technique

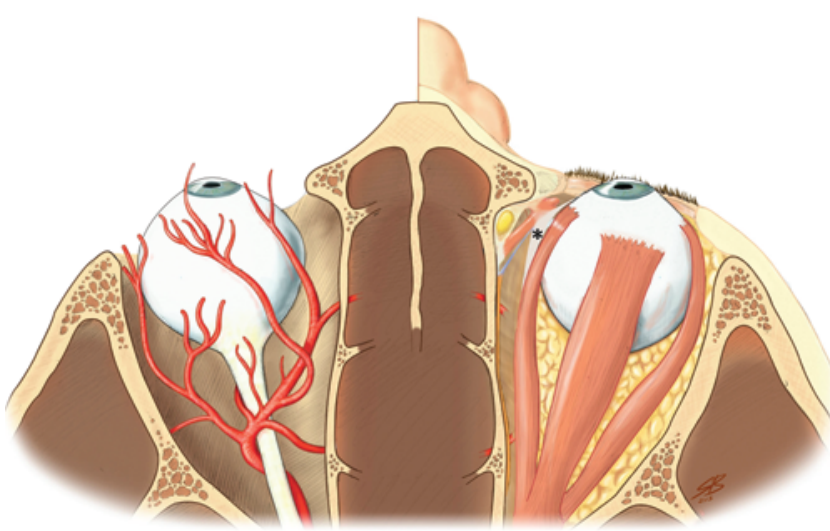

FIG. 4. Axial illustration showing the orientation of the AEA and PEA in relation to the optic nerve and the ophthalmic artery (left) and surgical anatomy illustrating the working corridor for the Lynch/transcaruncular approaches (right). Note the lacrimal sac (yellow) in relation to Horner's muscle and the orbital septum (blue line) located medially, with Tenon's capsule (white/asterisk) situated laterally. The avascular plane between Horner's muscle and the orbital septum leads to the frontoethmoidal junction, the cardinal landmark in this procedure. Note the medial periorbita (orange) and relationship of the anterior and posterior ethmoidal arteries accessed by a subperiorbital dissection. Copyright Robert T. Geertman. Published with permission.

most commonly used for decades. A vertical incision of about $3 \mathrm{~cm}$ midway between the medial orbital canthus and the nasal bridge is performed, and dissection is medial to the medial canthal tendon and deep to the lacrimal apparatus to expose a large portion of the medial orbital wall (Fig. 5). Dissection is then carried along the medial orbital wall to locate the frontoethmoidal suture line. Identification of this important bony landmark is a key step to follow during dissection. The lacrimal sac is the lower extent of dissection, but once the frontoethmoidal suture line is seen, dissection along this line posteriorly will yield the AEA. The main drawbacks of the Lynch approach are the need for a cutaneous incision, possible canthal webbing, and damage to the lacrimal drainage system. Scar formation has been partially addressed through modifications including a Z-plasty, though scarring may still occur. ${ }^{11}$ Recently, Douglas and Gupta described an endoscope-assisted Lynch approach through a $1-\mathrm{cm}$ incision with a favorable cosmetic outcome. ${ }^{9}$

The transcaruncular approach avoids the risk of a facial scar and has gained popularity for the ligation of the $\mathrm{AEA}^{32,38}$ (Fig. 5). A hook retractor is used to expose the caruncle just lateral to Tenon's capsule and the edge of the conjunctiva. An incision is made on the lateral one-third of the caruncle, exposing a thick avascular fibrous fascia. This condensed tissue represents the insertion site of the medial palpebral ligament anteromedially, Horner's muscle and the medial orbital septum posteromedially, and Tenon's capsule laterally. While retracting the globe laterally, careful palpation of the lacrimal crest is performed and dissection is carried posteriorly within the avascular plane between Horner's muscle and the orbital septum to the frontoethmoidal junction. Subperiorbital dissection along the medial orbital wall can then be performed in a posterior fashion to expose the AEA, which is typically located approximately $24 \mathrm{~mm}$ posterior to the lacrimal 


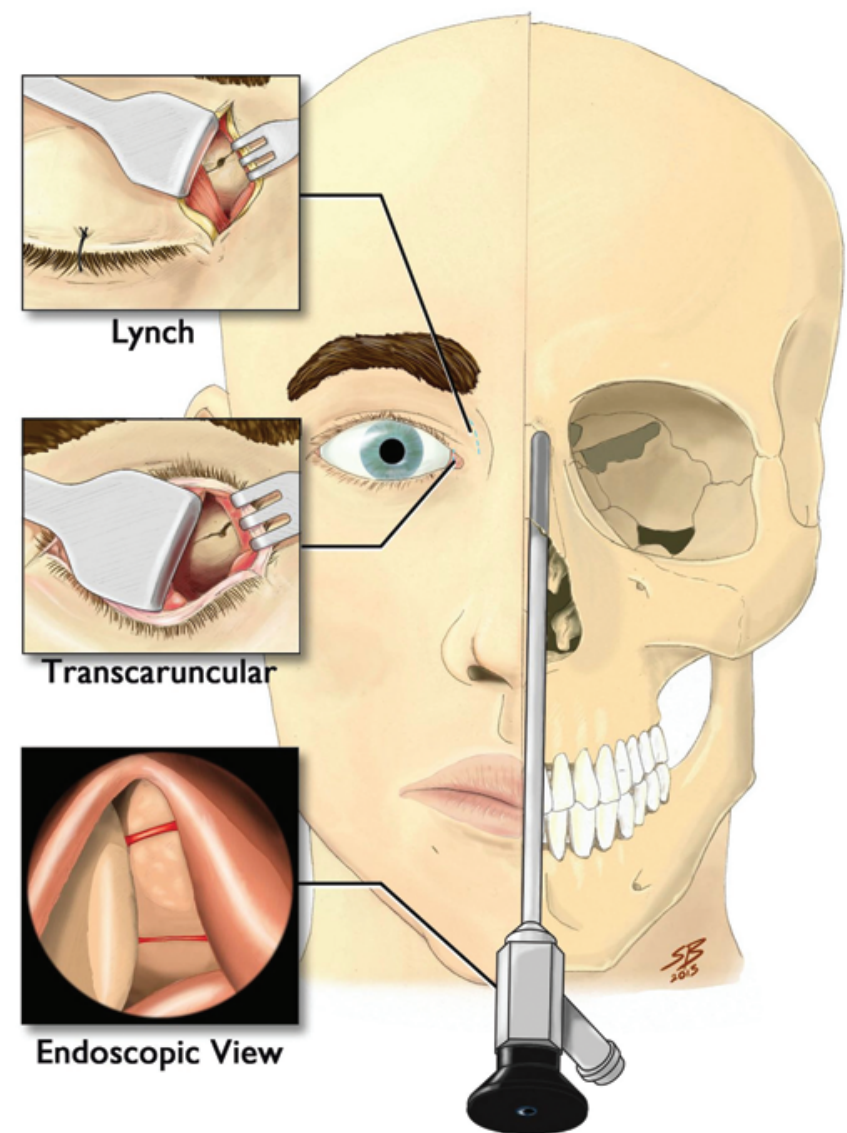

Fig. 5. Illustration. The surgical incision lines of the Lynch and transcaruncular approaches to the AEA are shown on the right (anatomical) side as surface landmarks. The endoscopic approach to the AEA via the patient's left (anatomical) nostril is demonstrated with the middle turbinate as a surgical landmark. Note also the frontoethmoidal suture in the base of the surgical wound in the Lynch and transcaruncular approaches; the latter provides the same exposure, obviating the need for a cutaneous incision and hence avoiding secondary facial scarring. Copyright Robert T. Geertman. Published with permission.

crest. Following identification of the AEA, hemostatic clip application and bipolar coagulation of the vessel are performed. With gentle retraction and periorbital dissection, exposure can be continued posteriorly to expose the PEA. This is a more demanding procedure because the PEA is of small caliber and is found near the orbital apex.

There are anatomical variations in the position and arrangement of the AEA and PEA. The AEA enters the anterior ethmoidal canal at the frontoethmoidal suture. While some individual variation exists with regard to the precise location of the anterior ethmoidal structures, numerous studies have described multiple anatomical landmarks to aid in the intraoperative identification of the foramen, canal, and artery. ${ }^{10,20,28,31}$ A literature review of anatomical references that can be used to help identify the anterior ethmoidal artery and canal is presented in Table 1, with distances measured from the anterior crest of the nasolacrimal fossa, anterior axilla of the middle turbinate, anterior nasal spine, and the anterior face of the ethmoidal bulla. Similarly, the PEA can be identified based on the distance from the nasion, the optic foramen, or the anterior ethmoidal foramen as shown in Table 2. We have also studied the patterns of AEA foramina in preserved human skulls at the Hamann-Todd Osteological Collection at the Museum of Natural History, Cleveland, Ohio, and observed 4 discrete patterns of anatomical variation of the AEA foramina with 1-4 ostia (Fig. 6) originally proposed by Caliot et al. ${ }^{4}$ The presence of a single foramen may be explained by the absence of the PEA, whereas 3 or 4 foramina imply the existence of supplementary arteries. The classic type had 2 ostia and was found in $80 \%$ of cases, and an isolated anterior ostium was found in only $2 \%$ of cases, as noted by Caliot et al. ${ }^{4}$

Some neurosurgeons use an extended endonasal endoscopic approach (EEEA) to resect midline anterior skull base meningiomas, particularly when they are smaller. Experiences in endoscopic surgery for frontal sinusitis and orbital decompression have added significantly to the progress in minimally invasive cranial base surgery. ${ }^{29,30,37,49}$ Once considered an adjunct to microsurgical techniques, the EEEA now has become an evolving alternative in many centers in achieving resection through a smaller corridor to decrease patient morbidity. Kassam et al. described some of the advantages of the EEEA in comparison with traditional transcranial approaches include reduction in the extent of bone resection, elimination of brain retraction, and less manipulation of neurovascular structures. ${ }^{16-18}$ One technique known as a modified Lothrop (Draf 3) procedure is performed by drilling out the entire floor of the frontal sinus and connecting the 2 frontal sinuses into a common cavity by removing the intervening septum.,48 This procedure enhances endoscopic access to olfactory meningiomas since the anterior limit of transnasal dissection for olfactory tumors is the posterior wall of the frontal sinus. ${ }^{15}$ The primary advantages of a modified Lothrop procedure are

TABLE 1: Anatomical landmarks in the literature for identifying the AEA*

\begin{tabular}{llc}
\hline \multicolumn{1}{c}{ Authors \& Year } & \multicolumn{1}{c}{ Distance } & Length \\
\hline Floreani et al., 2006 & from skull base to AEC & $2.9 \mathrm{~mm}(\mathrm{rt}) ; 2.00 \mathrm{~mm}(\mathrm{It})$ \\
McDermott et al., 2005 & from anterior crest of nasolacrimal fossa to AEF & $24 \mathrm{~mm}$ \\
Araujo Filho et al., 2006 & from the anterior axilla of the middle turbinate to AEA & $21.1 \mathrm{~mm}$ \\
& from anterior nasal spine to AEA & $61.7 \mathrm{~mm}$ \\
& from anterior nasal axilla to AEA & $64 \mathrm{~mm}$ \\
Lund \& Stammberger, 2008 & from the highest point of the anterior face of the ethmoid bulla & $1-2 \mathrm{~mm}$ \\
\hline
\end{tabular}

* $\mathrm{AEC}=$ anterior ethmoidal canal; $\mathrm{AEF}=$ anterior ethmoidal foramen. 
TABLE 2. Anatomical landmarks in the literature for identifying the PEA*

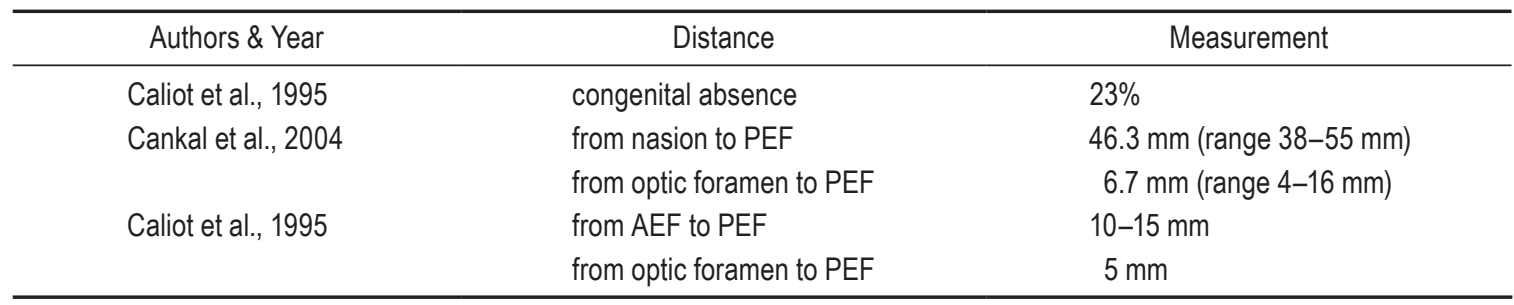

* PEF = posterior ethmoidal foramen.

enhanced visualization, easier repair of the skull base defect, and reduced potential for mucocele formation. An EEEA for anterior skull base meningiomas with transsphenoidal, transplanum, and transcribriform modifications offer a keyhole basal craniectomy for successful resection of these tumors, with a posterior nasoseptal flap to prevent CSF leakage. ${ }^{16-18,23}$ In contrast, a recent review by Komotar et al. reported a decrease in postoperative complications (for example, CSF leakage) and higher rates of achieving a gross-total resection for open transcranial resection of olfactory groove meningiomas when compared with endoscopic resection. ${ }^{21}$

We have used the transcranial approach for tumor resection, although we agree with the use of an EEEA in selected patients. We feel that the endoscopic endonasal approach is a feasible method to ligate the ethmoidal arteries while obviating the need for external incisions. While this procedure avoids visible scars, lack of a dehiscent anterior ethmoidal canal or a bony mesentery can make it technically unfeasible in some patients. Control of the AEA can be effectively achieved with the use of
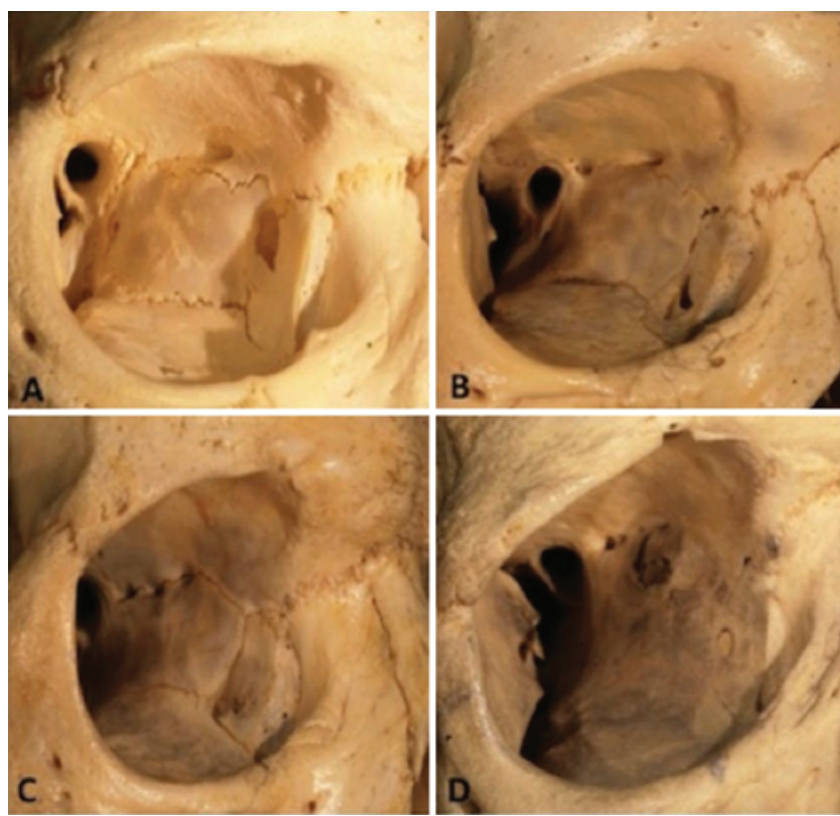

FIG. 6. The patterns of AEA foramina in preserved human skulls at the Hamann-Todd Osteological Collection at the Museum of Natural History, Cleveland, Ohio, which verified the 4 discrete patterns of anatomical variations of the AEA foramina with 1-4 ostia initially proposed by Caliot et al. a rigid $30^{\circ}$ endoscope for visualization and creating access via an anterior ethmoidectomy (Fig. 5). The AEA can be controlled endoscopically using bipolar cauterization, and vascular clips are not always necessary. Extreme caution must be exercised to carefully secure the AEA during ligation to prevent vessel retraction into the orbit, which can subsequently result in a retroorbital hematoma with visual compromise. In the majority of cases, the AEA is located high in the skull base, posterior to the frontal sinus opening but may also be found lower (in a mesentery) and can therefore be injured during routine sinus surgery. It is also not uncommon to find a dehiscent AEA during these approaches, which in turn makes clipping easier (Fig. 7).

Preoperative planning for localization of the AEA can be aided with the use of 3D CT reconstruction, and Keros grading ${ }^{19}$ can help to safely estimate the extent of drilling needed for AEA exposure. The Keros classification system describes the depth of the olfactory fossa in terms of the height of the lateral lamella: Type 1 refers to a depth of 1-3 mm, Type 2 a depth of 4-7 mm, and Type 3 a depth of 8-16 $\mathrm{mm}$. Almost three-fourths of the population falls into the second category. In regard to surgery, the classification is significant since the cribriform plate in patients with a Type 3 olfactory fossa is more prone to bony involvement in tumors..$^{14,19}$ If the lateral lamella is classified as a Keros Type 2 or 3 , it is likely that the AEA will be found in a mesentery. After preoperative height

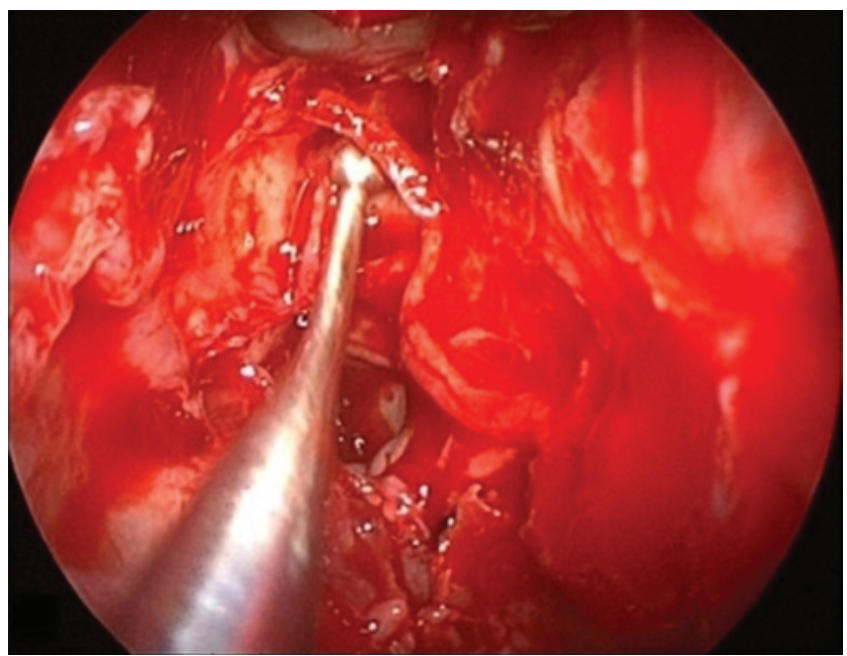

FIG. 7. Endoscopic image illustrating the AEA and dehiscence of the anterior ethmoidal canal. This condition is associated with a greater chance of effective clip application. 


\section{Ethmoidal artery ligation before meningioma resection}

TABLE 3: Advantages and disadvantages of open surgical versus endoscopic ethmoid artery ligation

\begin{tabular}{lll}
\hline Approach & \multicolumn{1}{c}{ Advantages } & \multicolumn{1}{c}{ Disadvantages } \\
\hline open surgical & familiarity; direct short trajectory & scarring, epiphora \\
endoscopic & cosmetically pleasing; natural corridor & learning curve, more set up time; more difficult to manage bleeding \\
\hline
\end{tabular}

determination of the lateral lamella of the cribriform plate and localization of the AEA, an ethmoidectomy can be performed to provide direct visualization of the AEA for ligation. ${ }^{12,36}$ In an expanded endonasal approach for resection of anterior skull base tumors, after maxillary antrostomy and removal of the uncinate process, the ethmoidal arteries are directly visualized lateral to the lamina papyracea. ${ }^{1,12,50}$ The PEA if present can be identified closer to the sphenoid sinus (Fig. 5).

Solares et al. reported that endoscopic AEA ligation could be cumbersome, and their study showed technical feasibility in only 3 of 16 sides. ${ }^{40}$ Their endoscopic ligation with preoperative $\mathrm{CT}$ scanning revealed that AEA ligation was less successful than was apparent. Effective AEA clipping was performed in $50 \%$ of cases with a mesentery. Endoscopic clipping was not technically feasible in cases of AEAs without a mesentery. Floreani et al. demonstrated that dehiscence of the anterior ethmoidal canal was associated with a greater likelihood of effective clip application..$^{13}$ In short, if the AEA is buried in the skull base, it can be technically challenging to effectively clip it because of the difficultly to safely obtain $360^{\circ}$ of exposure. Alternatively, AEAs can be ligated using bipolar cautery, but oftentimes this may not allow for adequate control of the vessel. Serious complications could result without achieving adequate control of the vessel, such as artery avulsion or retraction back into the anterior ethmoidal canal. In general, we do not advocate endoscopically clipping the AEA unless it is on a mesentery, which can be determined by preoperative CT studies. The AEA lies between the second and third lamella of the lateral nasal wall (ethmoidal bulla and middle turbinate, respectively). ${ }^{5}$ The AEA is usually located posterior to the anterior face of the ethmoidal bulla, unless a suprabullar recess exists. The PEA when present is smaller than the AEA and is commonly found at the junction of the roof of the sphenoid and posterior ethmoidal sinuses.

There are advantages and disadvantages of open surgical and endoscopic ethmoidal artery ligation (Table 3). An AEA external ligation can be done without and with
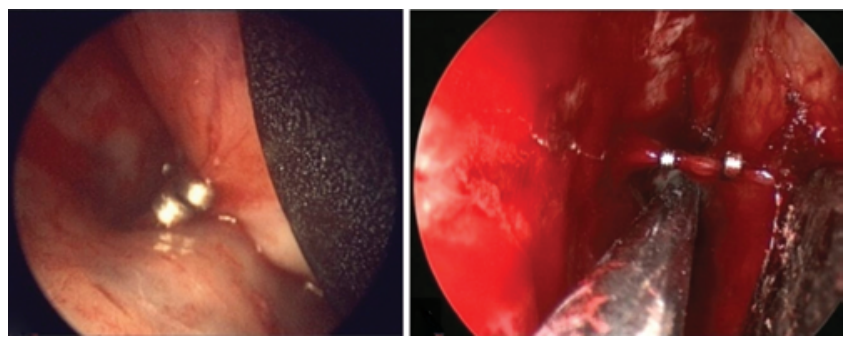

FıG. 8. Intraoperative photograph showing a left AEA clipped using an open surgical method (left, note the retractor in place) versus an endoscopically assisted external ligation technique via a Lynch incision (right). endoscopic assistance, with good clinical outcome (Fig. 8). The complications of surgical and endoscopic ligation of ethmoidal arteries are related to the procedure itself, especially with retraction of a partially coagulated vessel into the orbit or inability to control the vessel itself. The complications of this procedure vary from transient visual changes to a full-blown orbital apex syndrome due to retrobulbar hematoma. Brouzas et al. reported a case that depicted the potential peril of PEA cauterization in epistaxis producing traumatic optic neuropathy. ${ }^{3}$ The lessons learned from management of epistaxis by ligation of ethmoidal arteries have made a remarkable impact on the surgical techniques used in external ligation of these arteries prior to meningioma resection. ${ }^{39,42,45,47}$ However, we have only 3 patients with meningioma who were treated with this technique. It is therefore difficult to quantitate the efficacy of our procedure, as there are no external or internal controls.

\section{Conclusions}

Surgical ligation of AEAs and often PEAs prior to resection of large skull base meningiomas provides a safe and feasible option to limit blood loss during resection of hypervascular tumors. We describe both open surgical and endoscopic methods that may limit significant blood loss in partially embolized giant meningiomas of the anterior cranial fossa with relevant surgical anatomy. Additional preoperative devascularization of partially embolized lesions to limit blood loss makes intuitive sense; however, more, dedicated studies are warranted to evaluate comparative norms and reduction in blood loss afforded by ligation of ethmoidal arteries.

\section{Acknowledgments}

We sincerely acknowledge Stephen Buehrer's assistance with medical illustration and appreciate Lyman M. Jellema, Collections Manager, Department of Physical Anthropology, Cleveland Museum of Natural History, Cleveland, Ohio, for his assistance with skull specimens.

\section{Disclosure}

The authors report no conflict of interest concerning the materials or methods used in this study or the findings specified in this paper.

Author contributions to the study and manuscript preparation include the following. Conception and design: Geertman, Manjila, Chhabra. Acquisition of data: all authors. Analysis and interpretation of data: all authors. Drafting the article: all authors. Critically revising the article: all authors. Reviewed submitted version of manuscript: Geertman, Manjila, Cox, Smith, Corriveau, Chhabra.

\section{References}

1. Araujo Filho BC, Weber R, Pinheiro Neto CD, Lessa MM, 
Voegels RL, Butugan O: Endoscopic anatomy of the anterior ethmoidal artery: a cadaveric dissection study. Braz J Otorhinolaryngol 72:303-308, 2006

2. Bendszus M, Rao G, Burger R, Schaller C, Scheinemann K, Warmuth-Metz M, et al: Is there a benefit of preoperative meningioma embolization? Neurosurgery 47:1306-1312, 2000

3. Brouzas D, Charakidas A, Androulakis M, Moschos M: Traumatic optic neuropathy after posterior ethmoidal artery ligation for epistaxis. Otolaryngol Head Neck Surg 126:323325, 2002

4. Caliot P, Plessis JL, Midy D, Poirier M, Ha JC: The intraorbital arrangement of the anterior and posterior ethmoidal foramina. Surg Radiol Anat 17:29-33, 1995

5. Cankal F, Apaydin N, Acar HI, Elhan A, Tekdemir I, Yurdakul $\mathrm{M}$, et al: Evaluation of the anterior and posterior ethmoidal canal by computed tomography. Clin Radiol 59:1034-1040, 2004

6. Ciurea AV, Iencean SM, Rizea RE, Brehar FM: Olfactory groove meningiomas: a retrospective study on 59 surgical cases. Neurosurg Rev 35:195-202, 2012

7. Conger BT Jr, Riley K, Woodworth BA: The Draf III mucosal grafting technique: a prospective study. Otolaryngol Head Neck Surg 146:664-668, 2012

8. DeMonte F: Surgical treatment of anterior basal meningiomas. J Neurooncol 29:239-248, 1996

9. Douglas SA, Gupta D: Endoscopic assisted external approach anterior ethmoidal artery ligation for the management of epistaxis. J Laryngol Otol 117:132-133, 2003

10. Erdogmus S, Govsa F: The anatomic landmarks of ethmoidal arteries for the surgical approaches. J Craniofac Surg 17:280285, 2006

11. Esclamado RM, Cummings CW: Z-plasty modification of the Lynch incision. Laryngoscope 99:986-987, 1989

12. Felippu A, Mora R, Guastini L: Endoscopic transnasal cauterization of the anterior ethmoidal artery. Acta Otolaryngol 131:1074-1078, 2011

13. Floreani SR, Nair SB, Switajewski MC, Wormald PJ: Endoscopic anterior ethmoidal artery ligation: a cadaver study. Laryngoscope 116: 1263-1267, 2006

14. Gauba V, Saleh GM, Dua G, Agarwal S, Ell S, Vize C: Radiological classification of anterior skull base anatomy prior to performing medial orbital wall decompression. Orbit 25:9396, 2006

15. Huang BY, Lloyd KM, DelGaudio JM, Jablonowski E, Hudgins PA: Failed endoscopic sinus surgery: spectrum of CT findings in the frontal recess. Radiographics 29:177-195, 2009

16. Kassam A, Snyderman CH, Mintz A, Gardner P, Carrau RL: Expanded endonasal approach: the rostrocaudal axis. Part I. Crista galli to the sella turcica. Neurosurg Focus 19(1):E3, 2005

17. Kassam A, Snyderman CH, Mintz A, Gardner P, Carrau RL: Expanded endonasal approach: the rostrocaudal axis. Part II. Posterior clinoids to the foramen magnum. Neurosurg Focus 19(1):E4, 2005

18. Kassam AB, Gardner P, Snyderman C, Mintz A, Carrau R: Expanded endonasal approach: fully endoscopic, completely transnasal approach to the middle third of the clivus, petrous bone, middle cranial fossa, and infratemporal fossa. Neurosurg Focus 19(1):E6, 2005

19. Keros P: [On the practical value of differences in the level of the lamina cribrosa of the ethmoid.] Z Laryngol Rhinol Otol 41:809-813, 1962 (Ger)

20. Kirchner JA, Yanagisawa E, Crelin ES Jr: Surgical anatomy of the ethmoidal arteries. A laboratory study of 150 orbits. Arch Otolaryngol 74:382-386, 1961

21. Komotar RJ, Starke RM, Raper DM, Anand VK, Schwartz TH: Endoscopic endonasal versus open transcranial resection of anterior midline skull base meningiomas. World Neurosurg 77:713-724, 2012
22. Kunikata H, Tamai M: Cilioretinal artery occlusions following embolization of an artery to an intracranial meningioma. Graefes Arch Clin Exp Ophthalmol 244:401-403, 2006

23. Liu JK, Christiano LD, Patel SK, Tubbs RS, Eloy JA: Surgical nuances for removal of olfactory groove meningiomas using the endoscopic endonasal transcribriform approach. Neurosurg Focus 30(5):E3, 2011

24. Lund VJ, Stammberger H: Anatomy of the nose and paranasal sinuses, in Gleeson M, Browning GG, Burton MJ, et al (eds): Scott Brown's Otorhinolaryngology: Head and Neck Surgery, ed 7. London: Edward Arnold, 2008, Vol 2, pp 1315-1343

25. Martins C, Yasuda A, Campero A, Ulm AJ, Tanriover N, Rhoton A Jr: Microsurgical anatomy of the dural arteries. Neurosurgery 56 (2 Suppl):211-251, 2005

26. Mayfrank L, Gilsbach JM: Interhemispheric approach for microsurgical removal of olfactory groove meningiomas. Br J Neurosurg 10:541-545, 1996

27. McDermott MW, Rootman J, Durity FA: Subperiosteal, subperiorbital dissection and division of the anterior and posterior ethmoid arteries for meningiomas of the cribriform plate and planum sphenoidale: technical note. Neurosurgery 36: 1215-1219, 1995

28. McDonald SE, Robinson PJ, Nunez DA: Radiological anatomy of the anterior ethmoidal artery for functional endoscopic sinus surgery. J Laryngol Otol 122:264-267, 2008

29. Metson R, Dallow RL, Shore JW: Endoscopic orbital decompression. Laryngoscope 104:950-957, 1994

30. Metson R, Gliklich RE: Clinical outcome of endoscopic surgery for frontal sinusitis. Arch Otolaryngol Head Neck Surg 124:1090-1096, 1998

31. Moon HJ, Kim HU, Lee JG, Chung IH, Yoon JH: Surgical anatomy of the anterior ethmoidal canal in ethmoid roof. Laryngoscope 111:900-904, 2001

32. Morera E, Artigas C, Ferrán L, Trobat F, Tomás M: Transcaruncular electrocoagulation of anterior ethmoidal artery for the treatment of severe epistaxis. Laryngoscope 121:446450, 2011 (Erratum in Laryngoscope 121:1351, 2011)

33. Nania A, Granata F, Vinci S, Pitrone A, Barresi V, Morabito $R$, et al: Necrosis score, surgical time, and transfused blood volume in patients treated with preoperative embolization of intracranial meningiomas. Analysis of a single-centre experience and a review of literature. Clin Neuroradiol [epub ahead of print], 2013

34. Ojemann R: Meningiomas. Neurosurg Clin N Am 1:181-197, 1990

35. Perrini P, Cardia A, Fraser K, Lanzino G: A microsurgical study of the anatomy and course of the ophthalmic artery and its possibly dangerous anastomoses. J Neurosurg 106:142150,2007

36. Pletcher SD, Metson R: Endoscopic ligation of the anterior ethmoid artery. Laryngoscope 117:378-381, 2007

37. Ramakrishnan VR, Suh JD, Chiu AG, Palmer JN: Addition of a minimally invasive medial orbital approach in the endoscopic management of advanced sino-orbital disease: cadaver study with clinical correlations. Laryngoscope 121:437-441, 2011

38. Shorr N, Baylis HI, Goldberg RA, Perry JD: Transcaruncular approach to the medial orbit and orbital apex. Ophthalmology 107:1459-1463, 2000

39. Singh B: Combined internal maxillary and anterior ethmoidal arterial occlusion: the treatment of choice in intractable epistaxis. J Laryngol Otol 106:507-510, 1992

40. Solares CA, Luong A, Batra PS: Technical feasibility of transnasal endoscopic anterior ethmoid artery ligation: assessment with intraoperative CT imaging. Am J Rhinol Allergy 23:619-621, 2009

41. Spektor S, Valarezo J, Fliss DM, Gil Z, Cohen J, Goldman J, et al: Olfactory groove meningiomas from neurosurgical and 


\section{Ethmoidal artery ligation before meningioma resection}

ear, nose, and throat perspectives: approaches, techniques, and outcomes. Neurosurgery 57 (4 Suppl):268-280, 2005

42. Srinivasan V, Sherman IW, O’Sullivan G: Surgical management of intractable epistaxis: audit of results. J Laryngol Otol 114:697-700, 2000

43. Terada T, Kinoshita Y, Yokote H, Tsuura M, Itakura T, Komai $\mathrm{N}$, et al: Preoperative embolization of meningiomas fed by ophthalmic branch arteries. Surg Neurol 45:161-166, 1996

44. Turner T, Trobe JD, Deveikis JP: Sequential branch retinal artery occlusions following embolization of an intracranial meningioma. Arch Ophthalmol 120:857-860, 2002

45. Umapathy N, Quadri A, Skinner DW: Persistent epistaxis: what is the best practice? Rhinology 43:305-308, 2005

46. White DV, Sincoff EH, Abdulrauf SI: Anterior ethmoidal artery: microsurgical anatomy and technical considerations. Neurosurgery 56 (2 Suppl):406-410, 2005

47. Woolford TJ, Jones NS: Endoscopic ligation of anterior ethmoidal artery in treatment of epistaxis. J Laryngol Otol 114: 858-860, 2000

48. Wormald PJ: Salvage frontal sinus surgery: the endoscopic modified Lothrop procedure. Laryngoscope 113:276-283, 2003

49. Wormald PJ, Ananda A, Nair S: The modified endoscopic Lothrop procedure in the treatment of complicated chronic frontal sinusitis. Clin Otolaryngol Allied Sci 28:215-220, 2003

50. Yanagisawa E, Mirante JP, Christmas DA: Endoscopic view of the posterior ethmoid artery. Ear Nose Throat J 83:217218,2004

Manuscript submitted August 15, 2013.

Accepted October 10, 2013.

Please include this information when citing this paper: DOI: 10.3171/2013.10.FOCUS13327.

Address correspondence to: Robert T. Geertman, M.D., Ph.D., Department of Neurosurgery, MetroHealth Medical Center, Case Western Reserve University, Cleveland, OH 44109. email: rgeertman @metrohealth.org. 